\title{
Mencegah Trauma Pasca Bencana Gempa Bumi pada Anak dengan Terapi Rekreasional di Lombok Utara
}

\author{
Rias Pratiwi Safitri ${ }^{1}$, Pujiarrohman $^{2}$, Joko Jumadi ${ }^{3}$, Fitri Romadonika ${ }^{4}$, Eka Adithia \\ Pratiwi $^{5}$
}

rias_dangkem@yahoo.co.id ${ }^{1}$, jokojumadi@gmail.com², pujiarohman@gmail.com³ romadonika.fitri@gmail.com ${ }^{4}$, pratiwiekaadithia@gmail.com ${ }^{5}$

\author{
1,4,5 STIKES YARSI Mataram \\ ${ }^{2,3}$ Universitas Mataram
}

Article History:
Received: 13-06-2021
Revised: 09-07-2021
Accepted: $24-07-2021$

Keywords: Traumatic, Eathquakes, Recreational therapy

\begin{abstract}
Earthquakes that have occurred consecutively in Lombok since July 29, 2018 have had a tremendous impact on all aspects of the lives of disaster victims, both physical, social and psychological aspects. Various children's reactions to disasters according to the American Academy of Child and Adolescent Psychiatry (AACAP) depend on the damage suffered during the disaster. The death of a family member or friend is very traumatic, followed by the loss of family homes, schools, pets, and damage to the community. Therefore, efforts to implement recreational therapy in the form of fun-based games and games education is needed to help mental recovery of children, so as to prevent continuing trauma. After doing recreational therapy in 20 villages, it shows positive changes for the children to be more cheerful and require continuous therapy, especially those that support children's education and visual motor skills.
\end{abstract}

\section{Pendahuluan}

Bencana gempa bumi yang menimpa Lombok menyisakan kerugian, baik secara fisik maupun non fisik. Kerugian berupa non fisik meliputi adanya trauma yang dimiliki oleh korban, terutama adalah anak-anak. Trauma ini tidak bisa dibiarkan berlarut-larut terlalu lama karena akan berdampak buruk pada kehidupan korban. Gempa bumi secara konsisten terbukti berhubungan dengan masalah Kondisi Psikososial seperti depresi dan gangguan stres paska-trauma, sebuah survey menunjukkan bahwa, setelah peristiwa bencana, sekitar $15-20 \%$ populasi akan mengalami gangguan mental ringan atau sedang yang merujuk pada kondisi post-traumatic stress disorder (PTSD), sementara 3-4\% akan mengalami gangguan berat seperti psikosis, depresi berat dan kecemasan yang tinggi (Surendra et al, 2015).

Berdasarkan hasil observasi yang dilakukan oleh Relawan Sahabat Anak, Dampak langsung dari gempa bumi ini memaksa masyarakat untuk membangun tenda-tenda darurat untuk bisa bertahan hidup, Rumah-rumah warga sudah tidak bisa ditempati, tendatenda sederhana yang dibangun hanya mampu melindungi warga dari panas matahari, namun tidak dari derasnya hujan. Selain itu, angin kencang yang terus menerpa 
sesekali merusak tenda darurat yang dibangun. Trauma pasca bencana gempa bumi yang datang berkali-kali belum hilang dari diri korban, namun hal serangkaian kejadian terus terjadi dan semakin menambah trauma warga.

Secara umum terjadinya bencana gempa bumi memang mengakibatkan kerusakan, baik fisik maupun non-fisik. Pemerintah telah melakukan tindakan cepat dalam mengatasi kerusakan fisik. Namun sering terjadi di kondisi seperti ini perbaikan hanya berfokus pada sarana fisik, sedangkan kerusakan non-fisik seperti ada trauma yang dialami para korban belum banyak dilakukan. Rangkaian masalah diatas membuat masyarakat mengalami trauma yang mendalam, terutama anak-anak dan wanita.Trauma yang dialami para pengungsi terutama anak-anak ini akan menyisakan dampak psikologi yang cukup mengkhawatirkan jika tidak segera ditangani dengan tepat. Keceriaan anak anak akan hilang dan rasa takut akan terus menghantui mereka.

Bencana memiliki pengaruh terbesarpada kelompokyangpalingrentan terutama adalah kelompok usia anak-anak (Nakamura,2005). Hal ini disebabkan karenaanakanaksecaralangsungmengalami, merasakan, dan menyaksikan dampak yang ditimbulkan akibat faktor usia yangmasihbelum matangsecara pertumbuhanpsikologis. Rentang usia anak dalam usia dini adalah anak yang berada pada rentang usia 0-8 tahun menurut NAEYC (National Association fo $r$ The Education of Young Children). Pada usia 0 sampai 8 sebagai masa keemasan (golden age) dimana otak anak mampu berkembang hingga $80 \%$ tahun. Otak anak tersusun dari milyaran yang neuron saling berhubungan menghasilkan sebuah yang timbul akibat sinapsis adanya rangsangan dari lingkungan yang ditangkap oleh panca indra. Neuron yang terhubung ada yang dibuang dan ada yang disimpan. Yang dibuang adalah yang berasal dari sinapsis yang jarang. Bencan aalam dapat menjadi sebuah kejadian yang sangat berkesan bagi anak, disimpan dan teringat kuat dalam pikiran anak sehingga hal yang berkaitan dengannya (Taliningtyas, 2017).

American Academy of Child and Adolescent Psychiatry Berbagai reaksi anak akibat bencana menurut (AACAP, 1998) tergantung dari kerusakan yang dialami selama bencana itu terjadi. Kematian keluarga anggota atau teman menjadi hal yang sangat traumatis, dengan diikuti hilangnya rumah, keluarga, sekolah, peliharaan hewan, dan kerusakan di masyarakat dikemukakan oleh Speier (2000). Karena anak-anak merupakan pribadi yang unik berbeda dari orang dewasa, Reaksi psikologis umum yg terjadi pada anak korban bencana misalnya anak menjadi lebih sensitif, mudah marah, panik dan menangis, serta mereka sangat mudah menangis jika mendengar sesuatu yang bergemuruh. Selain itu anak-anak juga sering khawatir untuk memasuki rumahnya, mereka yang awalnya ceria namun setelah terjadi gempa menjadi sosok yang lebih banyak diam dan cenderung menarik diri dari lingkungan mudah marah, kesedihan yang mendalam, ansietas, kehilangan minat untuk makan dan minum/aktivitas dll. Anak-anak korban bencana alam https://journal.universitasbumigora.ac.id/index.php/ADMA 
memiliki karakteristik yang khas, sehingga memerlukan bentuk-bentuk intervensi yang sesuai dengan karakteristik dan tahap perkembangannya agar gangguan stress pasca trauma yang dialami dapat menurun.

Trauma anak bisa ditangaini melalui empat teknik, yaitu teknik relaksasi, teknik mengekspresikan emosi, teknik rekreasional, teknik ekspresif. Upaya penerapan terapi rekreasion ini memberikan keringanan beban pikiran yang dirasakan si trauma (orang), mengurangi rasa ketegangan, mengurangi rasa takut, menghapus memori yang membuat trauma terkait dengan bencana, memudarkan ingatan anak tentang benca yang pernah dirasa, dan membuat suasani hari menjadi lebih rileks, serta semakin baik memulihkan kondisi mental anak. Pada akhirnya, kehidupan anak dapat kembali normal dalam beberapa hari atau minggu setelah peristiwa yang mengerikan tersebut. Terapi rekreasional ini dapat berupa permainan dan games yang berbasis fun-education sangat dibutuhkan untuk membantu pemulihan mental anak sehingga mencegah terjadinya trauma yang berkelanjutan. Anak-anak perlu dirubah paradigmanya dari realitas yang menakutkan itu kepada realitas yang memberi harapan, bahwa masa depan mereka masih panjang, hidup harus terus berjalan dan kelak semua akan baik-baik saja. Selain itu dengan terapi rekreasional dapat membantu mengurangi ketegangan secara fisik akibat aktivitas anakanak yang terbatas di pengungsian.

Kegiatan pengabdian kepada masyarakat ini diharapkan dapat mengatasi trauma yang dihadapi oleh anak-anak pasca gempa bumi, sehingga anak-anak korba gempa bumi dapat menjalani kehidupan yang lebih baik dikemudian harinya.

\section{Metode}

Metode yang terkait dengan kegiatan pengabdian ini adalah pelatihan pada relawan sahabat anak serta penyuluhan sebelum turun ke daerah bencana. Selanjutnya diberikan permainan (play therapy), dan self motivation. Adapun tahap-tahap pelaksanaan kegiatan adalah sebagai berikut: Pertama, tim memberikan pelatihan kepada relawan Sahabat Anak yang di bagi dalam kelompok-kelompok yang terdiri dari 6-12 orang yang diturunkan di 20 desa di Kabupaten Lombok Utara. Kedua, pelaksanaan. Dimana tahap ini diimplementasikan dalam bentuk nyata melalui permainan (play therapy) dan self motivation.

Kegiatan pengabdian ini lebih menekankan pada permainan yang sarat akan muatan edukasi. Kegiatan permainan dilakukan secara kelompok. Bermain menjadi metode yang tepat untuk anak dikarenakan melalui terapi bermain (play therapy) sama saja dengan mengajak anak untuk bermain. Maksudnya mempengaruhi anak untuk tergabung dalam permainan yang ditawarkan. Sehingga anak-anak merasa menikmati situasi yang sedang terjadi walaupun tidak senyaman seperti biasanya sebelum bencana 
gempa bumi terjadi. Selanjutnya, metode yang digunakan adalah motivasi diri (selfmotivation).

\section{Pembahasan}

Kegiatan terapi rekreasional ini merupakan salah satu dari rangkaian kegiatan pengabdian masyarakat yang dilaksanakan pada hari Kamis, tanggal 20 Sepember 2018. Berlokasi di posko daerah bencana yang ada di 20 Desa di Kabupaten Lombok dengan melibatkan anak-anak di daerah bencana, Relawan Sahabat Anak, serta tim pengabdian STIKES Yarsi Mataram dan Universitas Mataram. Pelatihan diberikan oleh Rias Pratiwi Safitri, M.Psi,Psikolog dan Pujiarohman,M.Psi.,Psikolog.

Terapi rekreasional yang dilakukan bertujuan untuk menurunkan tingkat kecemasan dan mengembalikan kondisi emosional anak-anak pasca bencana gempa bumi dengan berbagai macam permainan yang dilakukan secara individu maupun kelompok. Kegiatan ini disambut dengan baik oleh anak-anak yang ada di psoko yang mengikuti kegiatan pengabdian ini. Pelaksanaan terapi rekreasional dilakukan di poskoposko pengungsian. Kegiatan dilanjutkan dengan berbagai macam terapi permainan yang disampaikan oleh relawan sahabat anak yang sudah mendapatkan pelatihan. Terdapat beberapa metode pemulihan trauma yakni antara lain terdiri dari pemberian obat dan terapi psikis (Todahl dkk., 2014). Terapi psikis dibedakan untuk anak-anak dan orang dewasa. Bentuk terapi untuk orang dewasa adalah bimbingan konseling. Sementara terapi psikis untuk anak anak adalah play therapy, dengan memanfaatkan media permainan seperti tali tambang, balon udara, bola plastik, hulahop, buku gambar, pensil warna dan speaker. Dimana play terapy ini berfungsi untuk mengekspresikan emosi anakanak.

Dunia anak merupakan dunia yang hampir keseluruhannya berupa tindakan dan aktifitas. Bermain merupakan bahasa anak, anakakan memiliki imajinasi yang sangat luas dengan dunia bermainnya sendiri. Karenanya bermain menjadi salah satu metode yang cukup baik dalam mengatasi kecemasan pada anak. Beberapa studi dan riset yang berkenaan dengan peran dan fungsi permainan bagi proses perkembangan anak banyak ditemukan. Dapat disimpulkan bahwa terapi rekreasinal merupakan satu proses pemberian bantuan berupa penyembuhan untuk mengatasi gangguan psikologis seperti kecemasan, panik, dan gangguan lainnya karena lemahnya ketahanan fungsi-fungsi mental yang dimiliki individu korban bencana alam tersebut. Terapi Rekreasional merupakan salah satu kebutuhan utama khususnya bagi korban bencana, dengan terapi trauma healing korban diharapkan dapat berangsur pulih dari trauma yang dialami dalam hidupnya. Karena trauma merupakan sebuah kejadian emosional dan fisik yang dapat dikatakan serius karena mengakibatkan kerusakan substansial terhadap fisik 
dan psikologis seseorang dalam rentangan waktu yang relatif lama (Weaver, 2003). Trauma dapat menyebabkan kondisi emosional yang dapat berkembang dikarenakan adanya sebuah peristiwa yang kurang berkenan, menyedihkan, menyakitkan, menakutkan, mencemaskan dan menjengkelakan. Berikut contoh gambar pengabdian.
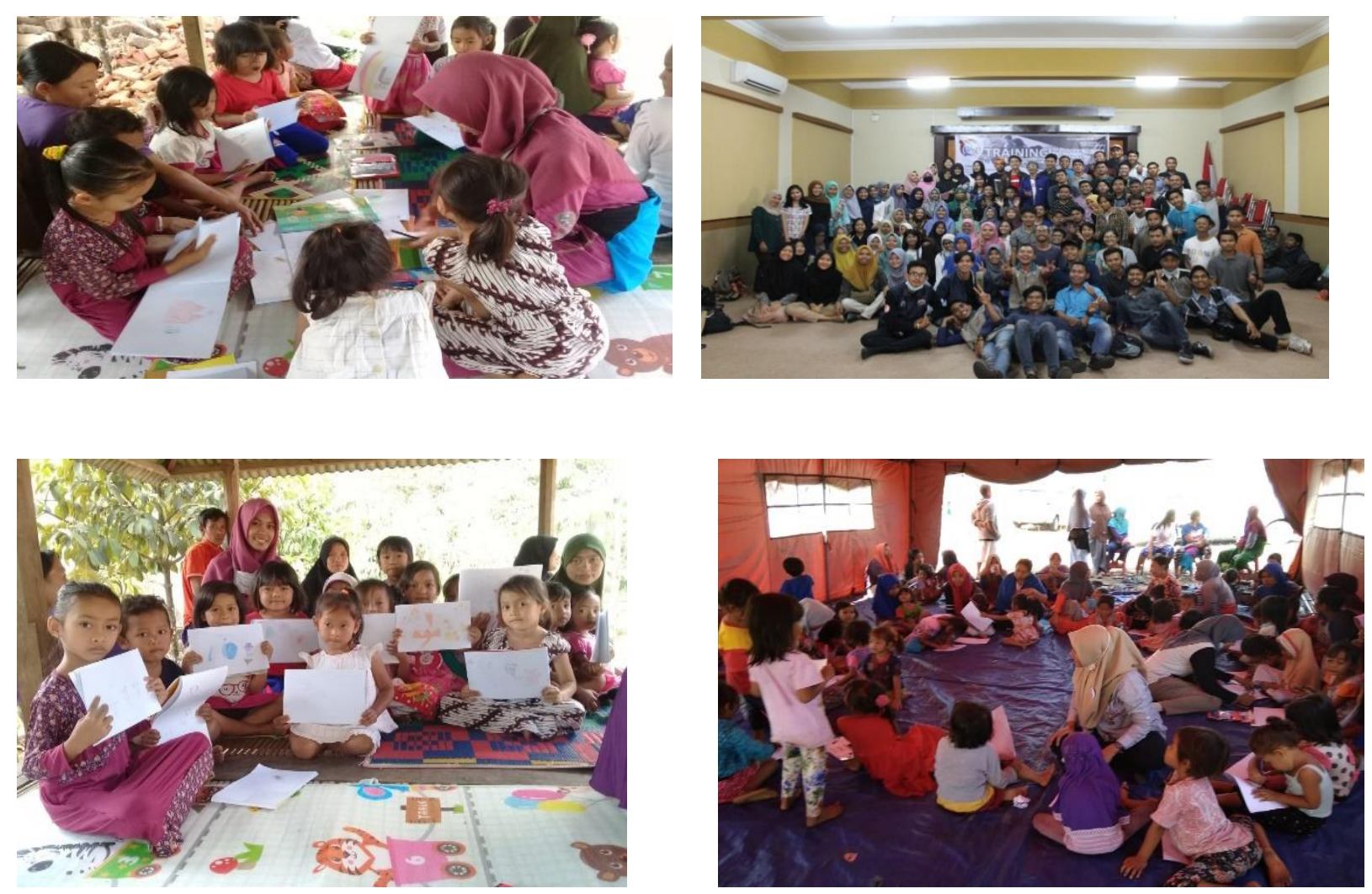

Gambar 1.Foto dokumentasi pengabdian

\section{Kesimpulan}

Terapi Rekreasional pasca gempa diperlukan penanganan khusus untuk menghilangkan trauma dan ketakutan sebagai efek psikis setelah terjadi bencana terutama kepada anak-anak. Penyembuhan trauma pada anak-anak pasca kejadian bencana yang telah dialami membutuhkan proses yang lama dan berkesinambungan. Walaupun kegiatan ini dilaksanakan dalam waktu yang terbatas tapi pesan yang disampaikan mampu diterima baik oleh anak-anak agar dapat mengembalikan senyuman mereka dalam menghadapi kehidupan yang ideal kedepannya. Kami berharap kegiatan ini dapat ditindak lanjuti oleh pihak-pihak terkait seperti dosen dalam melaksanakan pengabdian kepada masyarakat, tenaga kesehatan yang ada di puskesmas ataupun pelayanan kesehatan serta deteksi dini masalah psikososial, edukasi dan terapi bagi para korban bencana alam yang dilakukan oleh Tim relawan dan petugas kesehatan. 


\section{UcapanTerimakasih}

Terimakasih penulis ucapkan untuk seluruh Relawan Sahabat Anak yang telah berpartisipasi dalam kegiatan, serta tim pengabdian masyarakat dari STIKES Yarsi Mataram dan UniversitasMataram.

\section{Daftar Pustaka}

Ando, S., Kuwabara, H., Araki, T., Kenehara, S., Morishima, R., Kondo, S.,...Kasai, K. (2017). Mental health problems in a community after the great East Japan earthquake in 2011: A Systematic review. HarvardReview of Psychiatry, 25(1), 15-28.doi: 10.1097/HRP.000000

Astuti, B. (2006). Layananbimbingandankonselingbagikorbangempabumi di Yogyakarta.Makalah.JurusanPsikologi Pendidikan danBimbingan,

FakultasllmuPendidikan, Yogyakarta.BadanMeteorologidanGeofisika. 2018.

UniversitasNegeri

Bedriye, A. K. (2014). Determination and evaluation of effect of earthquake on school age children (6-12 years old) behaviours. Procedia-Social andBehavioural Science, 152, 845-851.doi: 10.1016/j.sbspro.2014.09.332

Fergusson, D. M., Horwood, L. J., Boden, J. M., \& Mulder, R. T. (2014). Impact of a major disaster on thementalhealthof a well-studied cohort. JAMA Psychiatry,71(9), 1025-31. doi:10.1001/jamapsychiatry.2014.65

Gurwitch, R. H., Kees, M., Becker, S. M., \& Schreiber, M. (2004), Assessment of PTSD among Indonesian children. Prehospital and Disaster Medicine, 46(5), 1921-8.

Hsu, C., Chong, M., Yang, P., \& Yen, C. (2002).Posttraumatic stress disorder among adolescent earthquake victims in Taiwan.APAPsycNET, 41(7), 875-881. doi: 10.1097/00004583-200207000-00022

Nakamura, Y. (2005). Public health impact of disaster on children.JMAJ, 48(7), 377-384.

Purnamasari, I. (2016). Perbedaanreaksianakdanremajapascabencana.JurnalPenelitiandanPengabdiankepad aMasyarakat, 3(1), 49-55.doi:10.32699/ppkm.v3i1.336

Ramirez, M., \& Peek-Asa, C. (2005).Epidemiology of traumatic injuriesfrom earthquakes.

Diperolehdarihttp://epirev.oxfordjournals.org/content/27/1/47.extract (online)

Reynolds, C. R. \& Richmond, B. O.(2008).(RCMAS $\left.{ }^{\mathrm{TM}}-2\right)$

RevisedChildren's Manifest Anxiety Scale ${ }^{\mathrm{TM}}$, Second Edition.Diperoleh darihttps:www.wpspublish.com/store/im ages/downloads/product/rcmas2_manual_chapter_1.pdf.

Şalcıoğlu, E., \&Başoğlu, M.. (2008). Psychological effects of earthquakes in children: prospects for brief

Data BPS Provinsi NTB (Lombok Utara DalamAngka 2008) Data dalamlaporankegiatan MDMC NTB. 2018 